\title{
A PRIMEIRA DÉCADA DE PRODUÇÃO CIENTÍFICA NAS PESQUISAS EM MÍDIAS E IDENTIDADES CONTEMPORÂNEAS DO POSCOM/UFSM
}

\author{
The first decade of scientific production \\ in the media and contemporary identities researches at the POSCOM/UFSM
}

La primera década de la producción científica en

investigación de medios e identidades contemporáneas en el POSCOM/UFSM

Docente da Universidade de Santa Cruz do Sul (UNISC) e pós-doutorando do Pós-Graduação em Comunicação da Universidade Federal de Santa Maria (POSCOM/UFSM)

brunokegler@gmail.com

Guilherme Oliveira Curi

Pós-doutorando e professor colaborador do Programa de Pós-Graduação em Comunicação da

Universidade Federal de Santa Maria (POSCOM/UFSM)

curi.guilherme@gmail.com

Camila Hartmann

Doutoranda do Programa de Pós-Graduação em Comunicação da Universidade Federal de

Santa Maria (POSCOM/UFSM) camilahartmann6@gmail.com

Helyna Dewes

Doutoranda do Programa de Pós-Graduação em Comunicação da Universidade Federal de Santa Maria (POSCOM/UFSM)

helyna.dewes@gmail.com

\section{Resumo}

$\mathrm{O}$ artigo analisa a produção científica da linha de pesquisa Mídias e Identidades Contemporâneas do Programa de Pós-Graduação em Comunicação (POSCOM) da Universidade Federal de Santa Maria (UFSM) durante a primeira década de publicações efetivas de dissertações de mestrado e teses de doutorado, entre 2008 e 2017. Foram analisados 66 trabalhos (56 dissertações e 10 teses) através do método pesquisa documental. Dentre os resultados, observou-se os principais autores utilizados (destacam-se Stuart Hall e Kathryn Woodward), o predomínio da abordagem qualitativa $(87,88 \%)$, a presença do problema de pesquisa $(80,30 \%)$ e do objetivo geral $(100 \%)$. Verificou-se as abordagens metodológicas recorrentes (análise do discurso e semiótica, etnografia, análise cultural-midiática), a descrição dos procedimentos metodológicos $(96,97 \%)$ e das técnicas de coletas de dados $(92,43 \%)$.

Palavras-chave: Produção Científica. Mídias e Identidades Contemporâneas.

POSCOM/UFSM

\section{Abstract}


The article analyzes the scientific production, during the first decade of effective publications of master's dissertations and doctoral theses, between 2008 and 2017, of the research line Medias and Contemporary Identities of the Post-Graduate Program in Communication (POSCOM) of the Universidade Federal de Santa Maria (UFSM). Using the documentary research method, this study analyzed 66 papers (56 dissertations and 10 theses). Among the results, we observed the main authors applied (Stuart Hall and Kathryn Woodward stand out), the predominance of the qualitative approach $(87.88 \%)$, the presence of the research problem $(80.30 \%)$ and the general objective $(100 \%)$. We verified the recurrent methodological approaches (discourse analysis and semiotics, ethnography, cultural-media analysis), description of methodological procedures $(96.97 \%)$ and data collection techniques $(92.43 \%)$.

Key words: Scientific production. Contemporary Media and Identities. Post-graduation in Communication.

\section{Resumen}

El artículo analiza la producción científica de la línea de investigación Medias e Identidades Contemporáneas del Programa de Posgrado en Comunicación (POSCOM) de la Universidade Federal de Santa María (UFSM) durante la primera década de publicaciones efectivas de disertaciones de maestría y tesis doctorales, entre 2008 y 2017. Se analizaron 66 trabajos (56 disertaciones y 10 tesis) mediante el método de investigación documental. Entre los resultados, observamos los principales autores utilizados (destacan Stuart Hall y Kathryn Woodward), el predominio del enfoque cualitativo $(87,88 \%)$, la presencia del problema de investigación $(80,30 \%)$ y el objetivo general $(100 \%)$. Se verificaron enfoques metodológicos recurrentes (análisis del discurso y semiótica, etnografía, análisis de medios culturales), descripción de procedimientos metodológicos $(96,97 \%)$ y técnicas de recolección de datos $(92,43 \%)$.

Palabras clave: Producción científica. Medios e Identidades Contemporáneas. POSCOM/UFSM

\section{INTRODUÇÃO}

Desde o início do século XX, diferentes intelectuais e pesquisadores tentaram entender os fenômenos comunicacionais, as relações socioculturais ligadas à mídia e as formas de interações mediadas nas sociedades modernas. Ao longo das décadas, diferentes perspectivas e linhas de estudos foram construídas em todo mundo em constante diálogo com o intenso e onipresente desenvolvimento tecnológico, manifesto em diversos tipos de organizações comunitárias, sociais, governos e estados nações.

Na América Latina, as pesquisas em Comunicação nasceram nos anos 1960 e 1970, no contexto de regimes autoritários, ditaduras civis, midiáticas e militares que fragilizaram a democracia em diferentes países (MARTINO, 2018). O estabelecimento e desenvolvimento dos meios de comunicação de massa naquela época foram aos poucos demonstrando a importância de se estudar o tema para de fato compreender os rumos das sociedades latino-americanas, assim como o Brasil.

De acordo com o Muniz Sodré, um dos precursores dos estudos comunicacionais no país, a comunicação revela-se como principal forma organizativa nas sociedades 
contemporâneas. Segundo o pesquisador, a comunicação significa "o fazer organizativo das mediações imprescindíveis ao comum humano, a resolução aproximativa das diferenças pertinentes em formas simbólicas" (SODRÉ, 2014, p. 15).

A partir da década de 1980, após o período ditatorial militar, a democracia foi reestabelecida no Brasil. Logo, escolas de comunicação se fortaleceram nas universidades, o que resultou também na criação de programas de pós-graduação, decorrentes do amadurecimento da comunicação como campo científico. Atualmente, são um pouco mais de cinquenta Programas de Mestrado e Doutorado, entre os quais está o Programa de PósGraduação em Comunicação (POSCOM) da Universidade Federal de Santa Maria (UFSM).

O POSCOM ${ }^{1}$ foi recomendado pela Comissão de Aperfeiçoamento de Pessoal Docente, da Coordenação de Aperfeiçoamento de Pessoal de Nível Superior (CAPES), em 17 de setembro de 2005, e criado pelo Conselho Universitário da UFSM em 18 de fevereiro de 2006. As atividades acadêmicas foram iniciadas no mês de março do mesmo ano, com o início das aulas do curso de Mestrado. Logo na primeira avaliação trienal, no quinto ano de funcionamento, o curso recebeu conceito de excelência 4. Em 2011, ao final do sexto ano de atividade, foi aprovado o curso de Doutorado, que iniciou as atividades em 2012. Já no final de 2013, com o doutorado efetivado, o programa ganhou o conceito de excelência 5, que permanece até hoje. Na época da implantação do curso de Doutorado, apenas quatro cidades do interior do Brasil possuíam esta formação acadêmica, a saber: São Bernardo do Campo e Campinas, no estado de São Paulo; Niterói, no Rio de Janeiro; e São Leopoldo, no Rio Grande do Sul (POSCOM, Online).

A área de concentração denominada Comunicação Midiática foi a escolhida para ser a base do POSCOM, que, de acordo com a Análise das Propostas de Cursos Novos, "compreende o estudo da ação midiática implicada na estruturação do espaço público, na visibilidade e legitimação das instituições e na configuração das identidades contemporâneas" (CAPES, 2006). Nesse sentido, o Programa majoritariamente objetiva, desde a sua criação, estudar as formas através das quais os meios de comunicação social - massivos ou não - incidem na associação, configuração e solidificação das relações sociais no tempo e no espaço.

Ainda nesta perspectiva, é necessário ressaltar que a área de concentração em Comunicação Midiática procura: evidenciar o campo das mídias; o ensino da comunicação em suas dimensões de produção, circulação e consumo; a incidência dessa comunicação, de suas

\footnotetext{
${ }^{1}$ Disponível em https://www.ufsm.br/cursos/pos-graduacao/santa-maria/poscom/apresentacao/. Acesso em 28 ago. 2020.
} 
lógicas e referências, sobre as práticas de outras instituições que recorrem aos seus parâmetros para os seus protocolos de comunicação no espaço público contemporâneo.

Logo, no bojo dessa amplitude de estudos, foram criadas duas linhas de pesquisa dentro do Programa de Pós-Graduação em Comunicação da UFSM. A primeira, chamada Mídias e Estratégias Comunicacionais, engloba estudos cuja abordagem permeie as estratégias que agem como promotoras da articulação e de organização entre a esfera midiática e os demais campos sociais e conta atualmente com dez docentes.

Já a segunda linha de pesquisa, foco deste artigo e sobre a qual iremos detalhar acerca da produção científica, denomina-se Mídias e Identidades Contemporâneas. Esta linha aglutina projetos de pesquisa que possuam em comum o estudo da incidência da esfera midiática na conformação das identidades contemporâneas com ênfase na construção de representações e significados. Ainda, tem por perfil agregar as pesquisas dos docentes que envolvem estudos interpretativos sobre o papel da Comunicação Midiática na construção de dinâmicas sociais, matrizes identitárias, experiências de interação e processos de consumo/apropriação que passam pela mediação do trabalho discursivo das linguagens midiáticas.

Atualmente, a linha conta com onze docentes, além de um professor colaborador, pósdoutorando do POSCOM e um dos autores deste trabalho, o Dr. Guilherme Curi. Os demais docentes são: Dra. Ada Cristina Machado Silveira; Dr. Cássio Tomain; Dr. Flavi Ferreira Lisboa Filho; Dra. Liliane Dutra Brignol; Dra. Márcia Franz Amaral; Dra. Milena Carvalho Bezerra Freire de Oliveira-Cruz; Dra. Rosane Rosa; Dr. Reges Tone Schwaab; Dra. Sandra Dalcul Depexe; Dra. Veneza Mayora Ronsini e Dra. Ana Carolina Escosteguy

Isto posto, neste artigo apresentamos os resultados obtidos através de uma análise estrutural das teses e dissertações elaboradas pelos discentes da linha de pesquisa Mídias e Identidades Contemporâneas entre 2008 e 2017. Em um primeiro momento, iremos tratar sobre o método aplicado. Em seguida, são apresentados os resultados do estudo. Por fim, detalhamos as conclusões resultantes das análises realizadas ao longo da investigação.

\section{PERCURSO METODOLÓGICO, COMPOSIÇÃO DO CORPUS E CRITÉRIOS DA ANÁLISE}

A presente pesquisa, quanto aos seus objetivos mais gerais, é classificada como exploratória (GIL, 2010). Este entendimento deriva da busca por maior familiaridade com o tema investigado e, assim, a consecução de um estado da arte que espelhe a primeira década da produção científica da linha de Mídias e Identidades Contemporâneas do POSCOM. Neste 
sentido, a coleta do material empírico seguiu os princípios da pesquisa documental, procedimento destinado à produção de conhecimentos, seja pela reinterpretação de dados a partir de uma angulação analítica inexplorada, seja para deslindar os modos como os conhecimentos têm sido produzidos.

Diante desses pressupostos, o primeiro passo foi a delimitação do período a ser pesquisado, estabelecendo-se um corte em relação ao horizonte total de teses e dissertações defendidas no POSCOM. O período contemplado foi de 2008 a 2017, incluindo-se todas as pesquisas defendidas e integralizando 56 dissertações e 10 teses (tabela 1). A busca ocorreu no repositório digital da UFSM, denominado Manancial, entre os dias 10 e 12 de agosto de 2020. Já a coleta de dados, nos trabalhos selecionados, deu-se entre 13 e 24 de agosto de 2020 . As análises, por fim, de 25 de agosto a 7 de setembro de 2020 .

Tabela 1 - Dissertações e teses por ano de publicação

\begin{tabular}{|c|c|c|c|}
\hline Ano da publicação & Dissertação (D) & Tese (T) & Total (D+T) \\
\hline 2008 & 5 & 0 & 5 \\
\hline 2009 & 3 & 0 & 3 \\
\hline 2010 & 4 & 0 & 4 \\
\hline 2011 & 9 & 0 & 9 \\
\hline 2012 & 7 & 0 & 3 \\
\hline 2013 & 3 & 0 & 4 \\
\hline 2014 & 4 & 0 & 6 \\
\hline 2015 & 6 & 4 & 13 \\
\hline 2016 & 9 & 6 & 12 \\
\hline 2017 & 6 & $\mathbf{1 0}$ & $\mathbf{6 6}$ \\
\hline Total & $\mathbf{5 6}$ & 0 & 7 \\
\hline
\end{tabular}

Fonte: elaborado pelos autores.

As 66 pesquisas foram submetidas à análise dos quatro autores deste artigo a partir dos seguintes critérios: a) objeto de pesquisa; b) tipo de pesquisa (qualitativa, quantitativa); c) natureza da pesquisa (exploratória, descritiva ou explicativa); d) questão de pesquisa (presente ou ausente); e) hipóteses (presentes ou ausentes); f) objetivo geral (presente ou ausente); g) 
justificativa acadêmica (presente ou ausente); h) referencial teórico - discussão do conceito de identidade; i) metodologia; j) descrição dos procedimentos metodológicos (presente ou ausente); k) técnicas de coletas de dados; 1) apresentação de limites do estudo; m) recomendações para pesquisas futuras.

Os critérios aproximam-se dos utilizados em estudo anterior dedicado à análise das teses e dissertações defendidas na linha de Mídia e Estratégias Comunicacionais, também referente ao período de 2008 a 2017 e publicada nesta edição da revista Animus (FOSSÁ et al., 2020). Faz-se, porém, algumas ressalvas. Não apresentamos os dados de validade de conteúdo dos instrumentos, tendo em vista que a informação está ausente em todos os trabalhos. Juntamente, na referida pesquisa, a presença de "estratégia" no título, resumo, palavras-chaves ou sumário era pré-requisito para a inclusão no corpus empírico, de forma a buscar a verificação da aderência com a linha de pesquisa Mídia e Estratégias Comunicacionais. Neste sentido, das 76 dissertações e teses inicialmente coletadas, restaram 63 após a aplicação desse filtro.

Diferentemente, não consideramos a presença do termo "identidade" como condicionante para a composição do corpus empírico, mas como critério de análise no item referencial teórico. Por isso, mesmo que "identidade" não estivesse no título, resumo, palavraschaves e sumário, mantivemos a dissertação ou tese na composição do corpus empírico. Tal opção se deve à verificação de que, em algumas dessas pesquisas, a noção de identidade foi objeto de discussão teórica, mesmo não estando nas partes supramencionadas. Assim sendo, entendemos que poderia haver prejuízo à análise do referencial teórico, que é onde mapeamos a presença do conceito de identidade, suas derivações e principais referências citadas. Ademais, cremos que a manutenção seja profícua para a sequência da pesquisa, que contemplará a análise dos objetos de estudo da linha Mídias e Identidades Contemporâneas, de 2008 a 2017, cuja publicação dos resultados está prevista para dezembro de 2020.

Composto o corpus empírico e definidos os critérios para a coleta de dados e a análise, compomos planilha única no software Excel para fins de identificação das pesquisas, organização e sistematização dos dados coletados. Diante dessas premissas, o formulário eletrônico foi estruturado com as seguintes colunas: a- Ano da publicação; b- Dissertação/tese; c- Autor (a); d- Título; e- Link (para acesso direto à dissertação ou tese); f- Orientador (a); gConceito de identidade aparece no título, resumo, palavras-chaves ou sumário? ( $\operatorname{sim} /$ não); hAbordagem e referências - quais conceitos de identidade e autores foram abordados?; i- Objeto de pesquisa; j- Tipo de pesquisa (quali, quanti ou quali e quantitativa); k- Natureza da pesquisa (exploratória, descritiva ou explicativa); 1- Questão de pesquisa (sim/não); m- hipótese de 
pesquisa (sim/não); n- Objetivo geral (sim/não), o- Justificativa (sim/não); p- Metodologia; qDescrição dos procedimentos metodológicos (sim/não); r- Técnicas de coleta de dados ( $\operatorname{sim} /$ não); s- Limites da pesquisa (sim/não); t- Recomendações para pesquisas futuras ( $\operatorname{sim} /$ não); u- Observações complementares.

\section{APRESENTAÇÃO E DISCUSSÃO DOS RESULTADOS DA PESQUISA}

Descritos os aspectos que balizaram a nossa investigação, iniciamos a apresentação e discussão dos resultados pelas classificações de pesquisa. De acordo com Gil (2010), o exercício de classificação responde à racionalidade humana. Aplicado ao campo científico, está atrelado a organizar e sistematizar saberes e disciplinas em áreas de conhecimento específicas. Deste modo, em razão da diversidade de objetos de estudos e de disciplinas, os critérios para subdivisão de pesquisas são variados, tais como a área de conhecimento, a finalidade, o nível de explicação e os métodos adotados.

Começaremos a discussão dos resultados mediante a apresentação do tipo e da natureza das pesquisas analisadas. Na sequência, tratamos da presença de hipótese, do problema, do objetivo geral e do objeto de pesquisa. Posteriormente, elucidamos o referencial teórico que baliza a reflexão sobre identidade nos trabalhos. Finalmente, trazemos os dados relativos à presença da justificativa acadêmica, às abordagens metodológicas utilizadas e aos limites e recomendações para investigações futuras.

\subsection{Do tipo e da natureza da pesquisa}

Em relação à elaboração da pesquisa científica, classificar consiste em delinear as etapas, otimizando o tempo e a utilização dos recursos disponíveis para a obtenção de resultados mais satisfatórios. Para este artigo, privilegiamos a análise de duas classificações, o tipo de abordagem e quanto aos objetivos mais gerais da pesquisa (GIL, 2010).

Para a primeira, buscamos se a dissertação ou tese seguia abordagem quantitativa, qualitativa ou quantitativa e qualitativa. De abordagem quantitativa, são estudos que realizam mensuração numérica, estatística de opiniões e de dados para a análise, tendo a sua ênfase descritiva. De abordagem qualitativa, são as pesquisas cujas conclusões não resultam da quantificação de respostas, mas da descrição e da explicação das variáveis coletadas. Integram esse grupo estudos que se utilizam de técnicas de coleta de dados como entrevistas em profundidade, grupos focais ou observações participantes. Ademais, são qualitativas as análises 
sobre o sentido da mensagem e suas relações com o contexto em que está inserida, tais como em notícias, anúncios publicitários e/ou imagens estáticas ou em movimento.

Do total de estudos analisados, é predominante a abordagem qualitativa, que representa 87,88\%. Em relação às dissertações, o percentual é ainda mais elevado, 92,86\%, o que corresponde a 52 estudos; enquanto que entre as teses tem-se o número de 6 (60\%). Com relação à abordagem quantitativa, entre as teses a representatividade é de $10 \%$, relativa a uma pesquisa, apenas. Entre as dissertações, não há a abordagem quantitativa. Entre as que conjugam quantitativa e qualitativa, 4 dissertações utilizam esta classificação, o que corresponde a 7,14\%. Entre as teses, o percentual chega a 30\%, correspondentes a 3 das 10 analisadas.

A predominância de pesquisas qualitativas, em nível de mestrado e de doutorado, é um caracterizador da linha de identidades, que está em íntima relação com outros aspectos analisados, tais como problemáticas e referenciais teóricos. É um indicador que sinaliza a constituição da linha de pesquisa mediante a reunião de estudos cujas questões não se debruçam à quantificação de dados para descrever um fenômeno comunicacional ou o contexto analisado, mas à compreensão das variáveis que levaram à materialização do objeto estudado, dos sentidos acionados, das condições de produção e de consumo. Logo, há uma profusão de estudos que se alinham teoricamente a autores da vertente culturalista, tais como Stuart Hall, do Centro de Estudos Culturais de Birmingham, e Néstor García Canclini, representante dos estudos culturais latino-americanos.

Em termos metodológicos, em consonância, são pesquisas que apresentam como metodologia e técnicas de coletas de dados, principalmente, etnografia, análise de discurso, análise semiótica, entrevistas em profundidade e observações participantes. O referencial teórico e as metodologias empregadas nos trabalhos serão detalhados posteriormente.

Já em relação à segunda classificação, buscamos se, de acordo com o propósito da pesquisa, ela se constituiria enquanto exploratória, descritiva ou explicativa. São exploratórias as pesquisas que objetivam proporcionar maior familiaridade com o problema, seja para tornálo mais explícito ou para construir hipóteses. Tem como técnicas de coleta de dados mais usuais a pesquisa bibliográfica, entrevistas em profundidade, a análise de exemplos que possam estimular a compreensão ou deslindar a problemática da investigação. Como observa Bonin (2006), os movimentos exploratórios podem ser diversos, incluindo levantamento de dados já existentes sobre o problema/objeto estudado, através de outras pesquisas já realizadas; usualmente envolvem uma ida ao campo, que não se traduz em deslocamentos espaciais, e incluem observações diretas sobre o material empírico, revisão bibliográfica, entrevistas com 
informantes-chaves e grupos focais, por exemplo, sendo que tudo isso pode ser utilizado para a construção do objeto, do referencial teórico e do problema de pesquisa, restringindo-se, aqui, às fases de elaboração da investigação científica.

Em virtude da sua flexibilidade, torna-se difícil cercá-lo para rotulá-lo, mas estudos de caso e levantamentos de campo podem ser compreendidos como exploratórios. Já as pesquisas descritivas definem-se pela descrição das características de um contexto ou população, estas mais afeitas às que tem objetivos profissionais, como referencia Gil (2010). Para ilustrar, neste grupo estariam inclusas investigações para identificar características de uma parcela de consumidores, buscando-se afinar os argumentos de venda, ou as que buscam o levantamento de variáveis para estabelecer inter-relações entre elas, como para compreender a preferência de voto de um determinado estamento social. Por fim, estariam tipificadas em pesquisas explicativas aquelas que se dedicassem a explicação de um fenômeno comunicacional e revestidas de elevado grau de controle, beirando o caráter experimental.

Do total de 66 pesquisas analisadas, todas foram enquadradas como exploratórias quanto aos seus objetivos mais gerais. Neste mote, admitimos certa dificuldade para alocar cada estudo em uma tipificação específica, devido à diversidade de finalidades de pesquisa verificadas e, também, à própria imprecisão das definições classificatórias. De qualquer forma, enquanto resultado, verifica-se que, por trajetórias distintas, há homogeneidade quanto aos objetivos mais gerais nas pesquisas da linha de Mídias e Identidades Contemporâneas.

\subsection{Da presença de hipótese, do problema, do objetivo geral e do objeto de pesquisa}

De acordo com Gil (2010), a hipótese pode ser entendida como uma suposição ou resposta provisória para o problema de pesquisa. Na sua forma mais simples, consiste numa expressão verbal que pode ser reconhecida como verdadeira ou falsa e pode desempenhar a função de nortear a pesquisa. Se, após o teste com procedimentos científicos específicos, reconhecer-se como verdadeira, passa a ser a resposta para o problema, podendo-se afirmar, então, que, sim, a hipótese foi validada. Se for refutada, não se anula a validade da pesquisa científica, pois segue sendo o resultado da investigação decorrente do uso de procedimentos específicos de coleta e análise dos dados. Porém, a ressalva em relação à assunção de resposta hipotética está na necessária atenção para que não se ignore a sua invalidação ou que se distorça os dados para confirmá-la.

Entre os estudos analisados, percebemos que há resultados contrários quanto à presença de hipótese de pesquisa em teses e em dissertações. Ao passo que nas teses ela está presente em 
apenas $3(30 \%)$ e não está em 7 (70\%), entre as dissertações são 35 (62,5\%) com resposta provisória para a questão problema e, sem, são 21 (37,5\%). Do universo total analisado, entre teses e dissertações, há hipótese em 38 (57,58\%) e não há em 28 (42,42\%). É, portanto, presente na maioria dos estudos desenvolvidos no período contemplado nesta investigação e, quanto à tendência inversamente proporcional entre teses e dissertações, é algo que carece de análise mais profunda em estudos posteriores para que se compreenda a razão.

Das fases da pesquisa científica, a problematização ocorre após a definição do tema ou assunto e consiste na formulação de perguntas que envolvam as dificuldades teóricas e/ou práticas que se pretende responder, podendo ou não ser acompanhadas de respostas provisórias (as hipóteses). Define-se pela articulação das questões norteadoras com um problema teórico, ou seja, o diálogo do pesquisador com autores e entre os autores acionados para a composição do referencial teórico. Nesta pesquisa, buscamos a presença explícita da questão-problema enquanto resultado da concatenação dos questionamentos teóricos, empíricos e metodológicos que norteiam a dissertação ou tese, com o pressuposto de que "a questão crucial constitui o problema de pesquisa que deve ser criteriosamente redigido" (LOPES, 2003, p. 138). Para ampliarmos o escopo da busca, consideramos, também, afirmações em que pudemos deduzir a questão central, mesmo que não estando na forma de interrogação.

Os resultados encontrados demonstram que em 46 dissertações, o que representa 82,14\% do total, a questão-problema é explícita, enquanto que não o é em 10 (17,86\%). Em relação às teses, a resposta é afirmativa para 7 (70\%) e negativa para $3(30 \%)$. Em relação aos índices totais, somando-se teses e dissertações, os índices correspondem a $53(80,30 \%)$ para a presença explícita da questão-problema e 13 trabalhos $(19,70 \%)$ não. Os resultados são expressivos positivamente, mas revelam uma lacuna a ser preenchida, tendo-se em vista a importância de dizer claramente a pergunta a que a pesquisa pretende responder - que é aquilo que justifica a sua razão de ser. Ademais, à questão-problema responde o objetivo geral da pesquisa, e, através dela, se define a metodologia e as técnicas de coleta e análise dos dados. Para o leitor, é um elemento essencial à compreensão do estudo, assim como o objetivo geral.

Ligado à formulação do problema, o objetivo geral pode ser definido como meta para todo o trabalho, em nível macro, enquanto que os objetivos específicos estão ligados à resolução de questões particulares da pesquisa e denotam operações processuais, etapas a serem superadas para a consecução do objetivo principal. Este, que deve ser exequível conforme as condições disponíveis para o pesquisador, pode conjugar diversas ordens: teórica, prática e empírica (LOPES, 2003). Ainda, é fundamental a "articulação orgânica dos objetivos com o problema 
da pesquisa, com a problematização que o sustenta e com o desenho metodológico da mesma" (BONIN, 2006, p. 26). Evidencia, assim, a tessitura sistêmica das fases da pesquisa científica, algo que, em síntese, ilumina a linha imaginária que entrelaça todas as fases.

Das 56 dissertações analisadas, apenas duas não apresentam explicitamente o objetivo geral da pesquisa. Em uma delas, há referência à consecução dos objetivos estabelecidos nas considerações finais, mas o autor não os elucida na introdução ou nas seções prévias do trabalho. Na outra, são citados quatro objetivos, em sequência, porém não ocorre distinção entre o geral e os específicos. Entre as particularidades das dissertações que continham o objetivo geral, verificou-se em uma a presença de dois objetivos gerais e, em outras duas, grafias distintas no resumo e na introdução, mas com equivalência de sentido. Entre as 10 teses, todas demarcam o objetivo geral. É de se exaltar, portanto, a constância do objetivo geral em 64 das 66 pesquisas analisadas, o que representa o índice total de $96,97 \%$.

A tabela 2 ilustra uma síntese da presença e/ou ausência da hipótese, do problema e do objetivo geral nas teses e dissertações analisadas. Apresentamos o número e a respetiva porcentagem considerando as 10 teses e as 56 dissertações separadamente e, na última coluna, o resultado total a par das 66 pesquisas.

Tabela 2 -Número e porcentagem relativos à presença e/ou ausência da hipótese, do problema e do objetivo geral nas teses e dissertações

\begin{tabular}{|c|c|c|c|c|c|c|c|c|c|c|c|c|}
\hline & \multicolumn{4}{|c|}{ Teses } & \multicolumn{4}{|c|}{ Dissertações } & \multicolumn{4}{|c|}{ Total } \\
\hline & \multicolumn{2}{|c|}{ Presente } & \multicolumn{2}{|c|}{ Ausente } & \multicolumn{2}{|c|}{ Presente } & \multicolumn{2}{|c|}{ Ausente } & \multicolumn{2}{|c|}{ Presente } & \multicolumn{2}{|c|}{ Ausente } \\
\hline & $\mathrm{N}^{\mathbf{0}}$. & $\%$ & $\mathbf{N}^{0}$. & $\%$ & $\mathbf{N}^{0}$. & $\%$ & $\mathbf{N}^{0}$. & $\%$ & $\mathbf{N}^{0}$. & $\%$ & $\mathrm{~N}^{0}$. & $\%$ \\
\hline Hipótese & 3 & $30 \%$ & 7 & $70 \%$ & 35 & $62,50 \%$ & 21 & $37,50 \%$ & 38 & $57,58 \%$ & 28 & $42,42 \%$ \\
\hline Problema & 7 & $70 \%$ & 3 & $30 \%$ & 46 & $82,14 \%$ & 10 & $17,86 \%$ & 53 & $80,30 \%$ & 13 & $19,70 \%$ \\
\hline Objetivo geral & 10 & $100 \%$ & $\mathrm{X}$ & $\mathrm{X}$ & 54 & $96,42 \%$ & 2 & $3,57 \%$ & 64 & $96,97 \%$ & 2 & $3,03 \%$ \\
\hline
\end{tabular}

\section{Legenda}

$\mathrm{N}^{\circ}$ :: número

$\%$ : porcentagem

Fonte: elaborado pelos autores.

Por fim, empreendemos a descrição da análise do objeto de estudo, delimitado, neste estágio da pesquisa, à verificação da presença de objeto empírico. Em consonância com Lopes (2003), compreendemos a importância da instância epistemológica e teórica em todas as fases da pesquisa científica, situando, assim, que o quadro teórico de referência é um balizador 
primordial, desde a definição do objeto de estudo até a manipulação analítica. Em suma, significa dizer que o "quadro de referência acaba delimitando teoricamente o problema de pesquisa e os alvos de toda a investigação" (LOPES, 2003, p. 137).

Partindo dessa premissa, a opção pela análise da pesquisa empírica (BRAGA, 2011) está em considerar que deslindar o objeto empírico a partir de uma perspectiva qualitativa ainda não-esclarecida do ambiente social exige orientação teórica pertinente do pesquisador. Tratase, por conseguinte, da assunção do objeto empírico como uma chave de acesso à compreensão do objeto de pesquisa, este teoricamente fundamentado. É uma imersão compromissada, cujas lentes interpretativas são previamente definidas. Ainda apoiados em Braga (2011), em nossa escolha, não há qualquer depreciação às pesquisas teóricas, mas o reconhecimento de que o estudo aprofundado de autores para a proposição de novas ideias exige uma experiência de pesquisa que, geralmente, mestrandos e doutorandos não têm. Outrossim, o tempo demandado pode não coincidir com o prazo de elaboração e defesa de uma tese ou dissertação.

Ainda, entendemos a importância da descoberta como algo relevante, as "descobertas efetivas sobre características intrigantes do mundo real" (BRAGA, 2011, p. 6). Neste sentido, estaria a necessária experiência de formulação teórica e interpretativa como elemento essencial à formação do pesquisador, algo que é diferente e inalcançável somente a partir de elaborações dedutivas e ensaísticas de teorias precedentes, por mais sofisticadas que possam ser.

Guiados por esses pressupostos, verificamos que as 66 pesquisas investigadas se estabeleciam em torno de um objeto empírico. Ou seja, a totalidade da produção acadêmica da linha Mídias e Identidades Contemporâneas, de 2008 a 2017, é constituída por pesquisas empíricas. É, portanto, nos termos de Braga (2011), um componente formador dos pesquisadores do programa a ser salientado. As pesquisas empíricas se debruçam sobre objetos muito variados, tais como telenovelas, séries televisivas, jornais impressos, comunidades em redes sociais online, anúncios publicitários, documentários, telejornais, anais de eventos acadêmicos, revistas, letras de músicas, e outros, localizando-se, também diversamente, nas instâncias da produção, do conteúdo e do consumo.

\subsection{Do referencial teórico}

Tratamos agora a respeito das referências teóricas utilizadas nos trabalhos a fim de discutir o conceito de identidade. Do total de 66 teses e dissertações analisadas, 55 o fazem, correspondendo ao percentual de $83,33 \%$. Trata-se de um indicador positivo, uma vez que a identidade é um conceito basilar da linha de pesquisa sobre a qual se debruça o presente artigo. 
Mapear os principais autores citados e vislumbrar como o conceito de identidade é articulado nos estudos ora analisados é um caminho importante para desvelar o perfil teórico mais marcante não só da linha Mídias e Identidades Contemporâneas, mas, a reboque e amplamente, do POSCOM, nesses dez anos de produção (2008-2017).

Por conseguinte, apenas $11(16,66 \%)$ pesquisas não problematizam teoricamente o conceito. Em 5 delas o termo identidade não aparece. As outras 6 fazem alusão à identidade, sem discuti-la conceitualmente, em articulação com outros termos, como identificação e representação, e correlacionando-a com as noções de sujeito e indivíduo, por exemplo.

É pertinente destacar as principais variações e/ou desdobramentos do conceito que aparecem nos 55 trabalhos que o problematizam. Para fins de análise, consideramos a partir de duas ocorrências e chegamos aos resultados dispostos no gráfico 1

Gráfico 1 - Variações do conceito de identidade

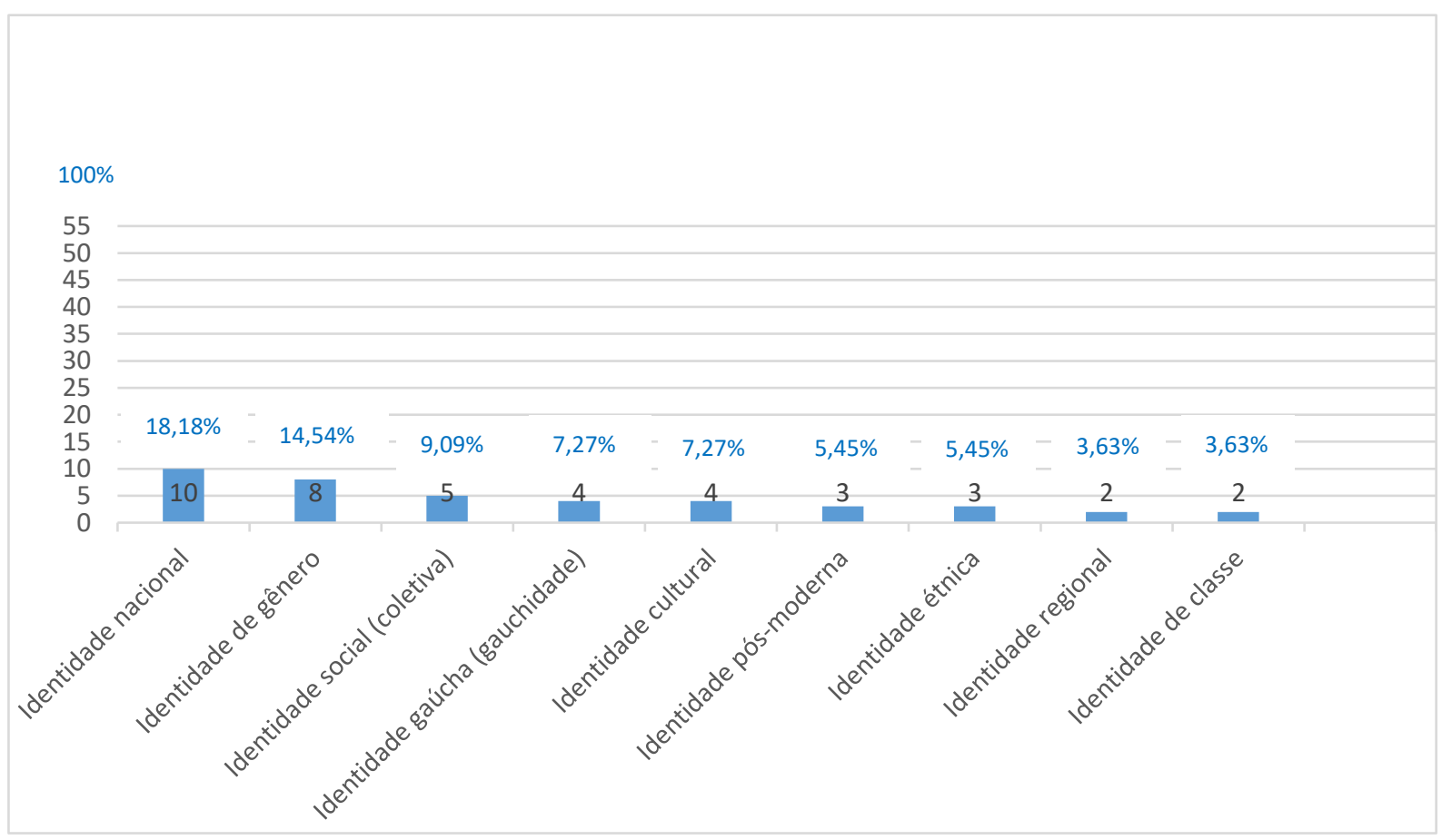

Fonte: elaborado pelos autores.

Conforme ilustra o gráfico 1, a identidade nacional é a variação mais recorrente nos estudos; aparece em 10 (18,18\%) deles, seguida da identidade de gênero, que é citada em 8 pesquisas $(14,54 \%)$, da identidade social (coletiva), referida em 5 trabalhos $(9,09 \%)$, da identidade gaúcha (gauchidade) e da identidade cultural, que empatam, cada uma debatida em 4 trabalhos $(7,27 \%)$, da identidade pós-moderna e da identidade étnica, também no mesmo 
páreo, cada qual com 3 ocorrências $(5,45 \%)$ e, finalmente, da identidade regional e da identidade de classe, especificadas em 2 estudos cada (3,63\%).

Há que se pontuar que alguns trabalhos enquadram a identidade social (coletiva), a identidade cultural, a identidade nacional e a identidade regional como equivalentes; isso ocorre especialmente na relação com a ideia de pertencimento a uma nação e de territorialidade. Nesses casos, classificamos o trabalho junto à ou às variações que foram de fato problematizadas - e não somente referidas em termos de sinonímia. Outras ponderações pertinentes: a identidade nacional inclui o debate sobre a brasilidade; a identidade de gênero envolve referências à identidade homossexual, a identidade lésbica e a identidade feminina; por fim, a identidade étnica engloba a discussão sobre a identidade negra.

Ainda sobre os desdobramentos do conceito, mesmo sem constituir uma variação explícita de identidade (como as elencadas acima), convém destacar algumas articulações teóricas empreendidas nas pesquisas. É frequente a relação entre identidade e: diferença e/ou alteridade, representação, discurso e usuários e redes. Também aparecem algumas reflexões sobre identidade de revista, de televisão ou de marca - nessas situações a identidade aparece quase sempre como sinônimo de imagem.

A tabela 3 apresenta os autores mais citados nas pesquisas ora analisadas no bojo da reflexão sobre identidade. Foram inclusos na tabela os autores citados em cinco ou mais trabalhos. Recorda-se que o percentual é correspondente ao total de 55 estudos que problematizam o conceito. A disposição dos nomes é em ordem decrescente (do mais citado até o menos citado).

Tabela 3 - Autores mais citados

\begin{tabular}{|l|l|l|}
\hline Autor(a) & $\begin{array}{l}\text { Número de trabalhos em } \\
\text { que é citado(a) }\end{array}$ & $\begin{array}{l}\text { Percentual } \\
\text { correspondente }\end{array}$ \\
\hline Stuart Hall & 40 & $72,72 \%$ \\
\hline Kathryn Woodward & 31 & $56,36 \%$ \\
\hline Manuel Castells & 19 & $34,54 \%$ \\
\hline Néstor García-Canclini & 19 & $34,54 \%$ \\
\hline Zygmunt Bauman & 17 & $30,90 \%$ \\
\hline Jesús Martín-Barbero & 16 & $29,09 \%$ \\
\hline Tomaz Tadeu da Silva & 14 & $25,45 \%$ \\
\hline Renato Ortiz & 9 & $16,36 \%$ \\
\hline
\end{tabular}




\begin{tabular}{|l|l|l|}
\hline Ana Carolina Escosteguy & 9 & $16,36 \%$ \\
\hline Muniz Sodré & 8 & $14,54 \%$ \\
\hline Denys Cuche & 8 & $14,54 \%$ \\
\hline Ada Cristina Machado Silveira & 7 & $12,72 \%$ \\
\hline Nilda Jacks & 7 & $12,72 \%$ \\
\hline Pierre Bourdieu & 6 & $10,90 \%$ \\
\hline Veneza Mayora Ronsini & 6 & $10,90 \%$ \\
\hline Douglas Kellner & 6 & $10,90 \%$ \\
\hline Homi K. Bhabha & 5 & $9,09 \%$ \\
\hline Beatriz Sarlo & 5 & $9,09 \%$ \\
\hline Benedict Anderson & 5 & $9,09 \%$ \\
\hline
\end{tabular}

Fonte: elaborado pelos autores.

O maior destaque é Stuart Hall, citado em 72,72\% dos estudos. Põe-se de manifesto a grande adesão dos pesquisadores que compõem a linha de Mídias e Identidades Contemporâneas aos estudos culturais, incluindo a vertente latino-americana, representada por autores cuja aparição nos trabalhos também é expressiva: Néstor García-Canclini, citado em 19 trabalhos (34,54\%), e Jesús Martín-Barbero, referido em 16 (29,09\%), por exemplo.

Cabe também comentar a numerosa presença de pesquisas - mais da metade: 31 , precisamente - que aludem os preceitos de Kathryn Woodward, também representante dos estudos culturais. É também notória a alusão a Manuel Castells, mencionado em 34,54\% dos trabalhos, e Zygmunt Bauman, evocado em 30,90\% deles. Em sua maioria, os pressupostos teóricos destes dois últimos são convocados para embasar uma reflexão sobre a volatilidade das identidades na pós-modernidade ou na contemporaneidade, o que indica a forte presença do tema nas pesquisas desenvolvidas pela linha, ainda que indiretamente - já que a variação explícita "identidade pós-moderna" não se mostrou tão frequentemente debatida.

Importante salientar, além disso, que é marcante na fundamentação da discussão sobre identidade a referência a três professoras da linha, todas aparecendo em mais de $10 \%$ dos trabalhos. A saber: Ana Carolina Escosteguy, citada em 9 trabalhos (16,36\%), Ada Cristina Machado Silveira, aludida em 7 (12,72\%), e Veneza Ronsini, mencionada em 6 (10,90\%).

Excluídos da tabela mediante o critério de citação em pelo menos 5 trabalhos estão os seguintes autores: Raymond Williams e Alain Touraine (referidos em 4 trabalhos cada um); Angela Felippi, João Freire Filho, Sandra Pesavento, Vera França, Jorge Larrain, Frederic 
Jameson, Eric Landowski, Elizabeth Bastos Duarte, Flavi Ferreira Lisboa Filho, Judith Butler, Guaciara Lopes Louro, Roberto DaMatta, Édison Gastaldo, Dominique Wolton, Serge Moscovici e Patrick Charaudeau (mobilizados cada qual em 3 estudos); e, finalmente, Algirdas Julien Greimas, Ruben Oliven, David Harvey, Marilena Chauí, Alejandro Grimson, Angela Arruda, Alberto Melucci, Maria Glória Gohn, Raquel Recuero, Priscila Ferreira, Miriam de Souza Rossini, Heleieth Saffioti, Cynthia Andersen Sarti, Gilbero Freyre, Charles Taylor, Fransesco Casseti, Frederico di Chio, Berenice Bento, Jessé Souza, Joan Scott e Ana Luiza Coiro Moraes (referidos em 2 pesquisas cada).

Ainda sobre identidade, faz-se importante esclarecer que algumas dissertações e teses não declaram seu desenvolvimento no seio da linha de pesquisa Mídias e Identidades Contemporâneas do POSCOM. A linha de pesquisa não é mencionada em 15 trabalhos, correspondendo ao percentual de 22,72\%. Há 11 pesquisas (16,66\%) em que a linha não é citada na capa e/ou nos demais elementos pré-textuais, mas sim na introdução. Portanto, do total de 66 trabalhos, $40(60,60 \%)$ explicitam o pertencimento à linha como supostamente seria o ideal, na capa e/ou nos elementos pré-textuais. Esse dado sugere a necessidade de padronização das pequisas quanto à identificação da linha de pesquisa, pois é um dado relevante na identificação dos estudos em bancos de dados e repositórios, por exemplo.

\subsection{Justificativa acadêmica, metodologias, limites e recomendações para pesquisas futuras}

Em confluência com os principais pressupostos teóricos trabalhados nas pesquisas analisadas nos primeiros dez anos do POSCOM, apontamos que as justificativas da pesquisa estão relacionadas ao comprometimento teórico no campo comunicacional, ou seja, em como determinada pesquisa irá contribuir para o debate e construção teórica da comunicação, em diálogo com as teorias já estabelecidas, além também do compromisso social da pesquisa, da importância e relevância do tema para sociedade.

Destarte, com relação às justificativas das pesquisas, constatamos que 50 das 66 dissertações e teses avaliadas justificaram cientificamente seus trabalhos. Este número representa $75,75 \%$ dos trabalhos analisados.

É necessário ressaltar que as pesquisas científicas necessitam ter certos níveis de ineditismo, logo, é dever ético do pesquisador explicitar o que há de diferente em sua pesquisa. Neste sentido, segundo Martino, justificar uma pesquisa é mostrar sua importância, não somente sua utilidade ou aplicação imediata, mas "a maneira como ela se relaciona com outros estudos e com a realidade ao seu redor" (MARTINO, 2018, p. 71). Ou seja, a justificativa 
mostra como a pesquisa se relaciona com questões gerais, e, ao mesmo tempo, como ela contribui especificamente dentro de determinada área do conhecimento a partir dos pressupostos teóricos previamente construídos.

Isto posto, a fim de tratarmos sobre as abordagens metodológicas encontradas nas teses e dissertações da linha de pesquisa Mídias e Identidades Contemporâneas, recordamos que a pesquisa em Comunicação se caracteriza também pela diversidade de abordagens, teorias, procedimentos e recortes até aqui destacados, lembrando que a comunicação, hoje, ocupa uma “posição reflexiva sobre a vida social, se não com 'um' objeto claramente discernível, certamente com um 'nó' ou um núcleo objetificável, onde se entrelaçam problematizações diversas do que significa a vinculação ou a atração social” (SODRÉ, 2002, p. 222). Assim, o entrelaçamento de problematizações e o diálogo com outras áreas do conhecimento reflete a interdisciplinaridade dos estudos comunicacionais, acarretando conformações metodológicas também heterogêneas em suas constituições.

De acordo com Braga (2011), a metodologia da pesquisa representa o conjunto de decisões, são os caminhos trilhados conscientemente ao longo da pesquisa. A opção por uma abordagem metodológica reflete também o processo de formulação das perguntas, que define paradigmas, enfoques e ângulos utilizados para interpelação de um objeto. Ou seja, ao elaborar uma metodologia, o pesquisador testa a coerência e os resultados obtidos na prática da investigação.

Com relação às metodologias mencionadas e descritas nas dissertações e teses que compõem o levantamento realizado para o presente artigo, constatamos uma variedade importante no conjunto de procedimentos, tanto para coleta como para análise de dados. Buscamos elencar as abordagens metodológicas predominantes de forma abrangente, as quais, apesar de em alguns casos combinarem técnicas distintas, conformam-se por propósitos de pesquisa semelhantes.

Definimos, assim, as seguintes metodologias, agrupando os trabalhos por afinidade teórico-metodológicas e/ou por recorrência de técnicas de coleta e exame de dados: a) análise do discurso - relaciona pesquisas que utilizam categorias de análise advindas principalmente de Patrick Charaudeau, Michel Pêcheux, Mikhail Bakhtin; b) análise semiótica - inclui as pesquisas relacionadas à semiótica greimasiana e a outros autores da área, como Adair Caetano Peruzzolo; c) etnografia, etnografia da recepção e observação - nesta categoria relacionamos as teses e dissertações que utilizam de observação, observação participante, observação online, entrevistas e questionários com vistas à compreensão da recepção e do consumo cultural; d) 
análise fílmica - investigações que possuem esta denominação em sua metodologia e que compuseram o corpus a partir da técnica da decupagem; e) análise cultural-midiática - as teses e dissertações com a metodologia assim caracterizada utilizam-se como técnicas de exame do corpus a análise textual, análise de conteúdo e análise documental, partindo da compreensão dos circuitos culturais; f) outras metodologias - incluem-se aqui as pesquisas que não possuem afinidade com as categorias delineadas e que se estruturam metodologicamente por cartografias, análises documentais e bibliométricas, análises de narrativas, análises sóciohistóricas, entrevistas, mito-crítica e análise do imaginário e dos universos míticos. A seguir, os resultados dispostos no gráfico 2:

Gráfico 2 - Metodologias de pesquisa aplicadas

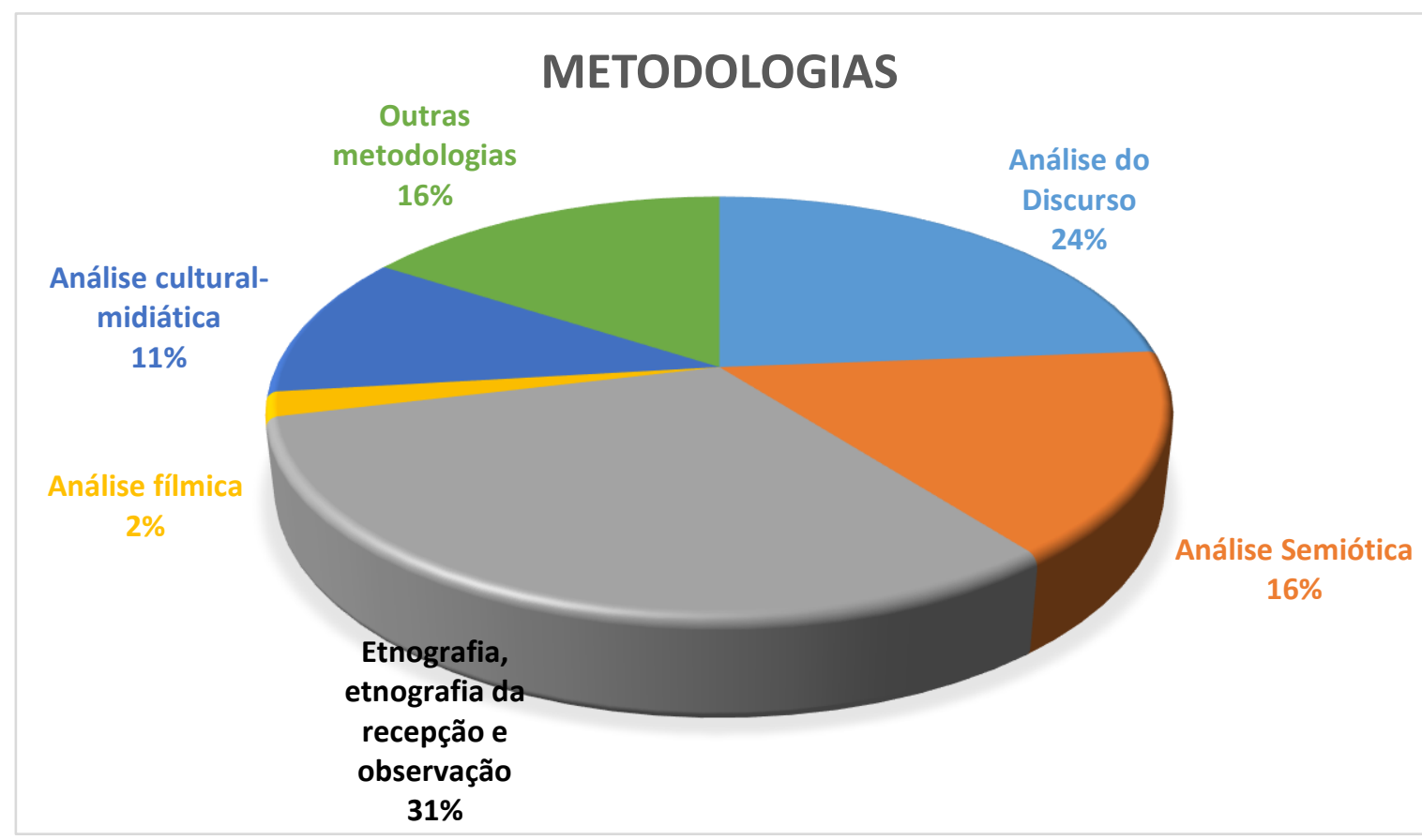

Fonte: elaborado pelos autores.

Com relação às metodologias abrangentes, entre os 66 trabalhos analisados, constatamos que as dissertações apresentam em maior número a metodologia relacionada à etnografia, etnografia da recepção e observação, com um total de 18 trabalhos. Na sequência, a análise do discurso aparece em 14 pesquisas, seguida por análise semiótica, com 8 , análise cultural-midiática com 6 , outras metodologias com igual número e, por fim, a análise fílmica, que corresponde a 4 dissertações. As teses em sua maioria trazem as abordagens metodológicas categorizadas como distintas das demais, perfazendo o total de 4 investigações. Em seguida, seguem a etnografia, etnografia da recepção e observação, juntamente com a análise semiótica 
constantes em 2 teses e a análise de discurso e a análise cultural midiática com 1 pesquisa para cada item relacionado.

A descrição dos procedimentos metodológicos adotados pelos pesquisadores nas investigações está presente na totalidade das dissertações analisadas. Contudo, observamos duas teses que indicam a metodologia utilizada, sem, porém, apresentar o detalhamento do caminho percorrido, sem descrever as técnicas tomadas para análise e coleta de dados.

Ainda, foi possível identificar as técnicas de coleta de dados na maior parte das pesquisas: $75,75 \%$ demonstram como obtiveram o corpus para as análises. Em números absolutos, 12 dissertações e 4 teses não expuseram de que forma foi possível a obtenção de dados para suas análises.

Com relação às considerações finais das pesquisas, tratamos de observar se foram descritos os limites da pesquisa e a recomendação para investigações futuras a partir do trabalho realizado. O relato ou a menção às limitações presentes nas teses e dissertações foi constatada em 39,39\% dos trabalhos. Em números absolutos, nas dissertações, os limites foram mencionados na menor parcela, ou seja, em 20 trabalhos do total de 56. Nas teses, a menção aos limites estava presente em maior parte, 6 trabalhos do total de 10 investigações. Já ao tratar da recomendação sobre pesquisas a serem desenvolvidas a partir das teses e dissertações, constatamos que 34 dissertações e 6 teses indicam a possibilidade de continuidade nas investigações, perfazendo um total de $60,60 \%$ dos trabalhos.

\section{CONSIDERAÇÕES FINAIS}

O mapeamento e a análise quantitativa e qualitativa dos 66 trabalhos de dissertação e tese defendidos entre os anos de 2008 e 2017 na linha de pesquisa Mídias e Identidades Contemporâneas do POSCOM da UFSM proporcionou uma visão mais clara e objetiva do perfil epistemológico, teórico e metodológico do programa nos primeiros dez anos de investigações científicas.

As principais áreas de interesse da linha, assim representadas nas dissertações e teses analisadas, foram: mídia, consumo e identidades (globalização e localização dos processos de comunicação e cultura; apropriações socioculturais da marca); representações midiáticas; recepção televisiva; abordagens culturais do jornalismo e o popular no jornalismo.

Destacaram-se importantes questões como o fato de Stuart Hall ser o principal autor citado nas pesquisas e estar presente em $72,72 \%$ das investigações analisadas. Logo, podemos inferir que tal fato justifica-se pela proximidade da linha com os Estudos Culturais Britânicos 
e por ser, Stuart Hall, um dos teóricos mais influentes nas discussões que englobam a relação entre identidade e meios de comunicação e suas formas de representação nas sociedades contemporâneas.

Ainda, outro ponto que chamou a atenção é o fato do método etnográfico, principalmente a etnografia da recepção e observação, estar presente em 18 trabalhos analisados. Tal metodologia, oriunda da Antropologia, comprova mais uma vez a capacidade interdisciplinar das pesquisas em Comunicação no Brasil, ainda incipientes, e o constante diálogo com as demais Ciências Sociais, principalmente nos primeiros anos de sua formação. Ainda, em relação às abordagens metodológicas, salienta-se sua correspondência direta com as principais áreas de interesse da linha, já mencionadas na introdução deste artigo.

Ressalta-se, também, a obtenção de indicadores positivos para todos os critérios analisados, ou seja, a necessária atenção aos aspectos teóricos e metodológicos da pesquisa científica é um caracterizador do conjunto de estudos que constituem a linha de pesquisa estudada. Ademais, são resultados que podem sinalizar reflexos profícuos à formação de mestres e doutores no POSCOM.

Por fim, é necessário salientar que a sequência desta pesquisa contemplará a análise pormenorizada dos objetos de pesquisa das teses e dissertações componentes do corpus empírico aqui discutido. A previsão de publicação da continuidade deste trabalho é para dezembro de 2020, também pela revista Animus.

\section{REFERÊNCIAS}

BONIN, J. A. Nos bastidores da pesquisa: a instância metodológica experienciada nos fazeres e nas processualidades de construção de um objeto. In: MALDONADO, A. E. (Org.). Metodologias de pesquisa em comunicação: olhares, trilhas e processos. Porto Alegre: Sulina, 2006.

BRAGA, J. L. A prática da pesquisa em Comunicação: abordagem metodológica como tomada de decisões. Revista da Associação Nacional dos Programas de Pós-Graduação em Comunicação |Ecompós. Brasília, v.14, n.1, jan./abr. 2011.

CAPES. Aplicativo para Propostas de Cursos Novos - APCN. Programa de Pós-Graduação em Comunicação, UFSM, 2006. Disponível em: http://www.capes.gov.br/avaliacao/cursosnovos-enviode-propostas-e-resultado. Acesso em: 30 ago. 2020.

FOSSÁ, M. I. T; SANTOS, M. C; FREIRE, G. D. A; MÜLLER, K. A.; MARTINS, A. F.; PREDIGER, S.; CAPORAL, G. L. S.; DALLA VALLE, T. F. Retrato de uma década de pesquisa do POSCOM/UFSM: um olhar para a produção científica da linha Mídia e Estratégias Comunicacionais. Animus. Santa Maria, v.19, n.20, p. 295-313, 2020.

GIL, A. C. Como elaborar projetos de pesquisa. 5 ed. São Paulo: Atlas, 2010. 
LOPES, M. I. V. Pesquisa em Comunicação. 7 ed. São Paulo: Edições Loyola, 2003.

MALDONADO, A. E. (Org.). Metodologias de pesquisa em comunicação: olhares, trilhas e processos. Porto Alegre: Sulina, 2006.

MARTINO, L. M. S. Métodos de Pesquisa em Comunicação: projetos, ideias, práticas. Petrópolis: Vozes, 2018.

POSCOM. Apresentação. Disponível em: bit.ly/3hdiita. Acesso em: 28 ago. 2020.

SODRÉ, M. Antropológica do espelho: uma teoria da comunicação linear e em rede. 2 ed. Petrópolis: Vozes, 2002.

SODRÉ, M. A Ciência do Comum. Rio de Janeiro: Vozes, 2014. 